\title{
Sub-seasonal precipitation forecasts using preceding atmospheric intraseasonal oscillation signals in a Bayesian perspective
}

Yuan LI ${ }^{1}$, Zhiyong WU ${ }^{1}$, Hai HE${ }^{1}$, Hao YIN ${ }^{1}$

${ }^{1}$ College of Hydrology and Water Resources, Hohai University, Nanjing 210098, China

Correspondence to: Zhiyong WU (wzyhhu@gmail.com)

Abstract. Accurate and reliable sub-seasonal precipitation forecasts remain challenging. The atmospheric intraseasonal oscillation (ISO), which is one of the leading sources of sub-seasonal predictability, could be potentially used as predictors for sub-seasonal precipitation forecasts.. However, the relationships between ISO signals and sub-seasonal precipitation are of high uncertainty. In this study, we first define potential predictors by analyzing the relationship between preceding atmospheric ISO signals and precipitation for 17 hydroclimatic regions over China during the boreal summer monsoon season. The Least Absolute Shrinkage and Selection Operator (LASSO) and stepwise regression approaches are used to narrow down the number of potential predictors. A Bayesian hierarchical model is then established to predict sub-seasonal precipitation. The model performance is evaluated through a leave one-year-out cross-validation strategy for both deterministic and probabilistic forecasts. The results suggest that the statistical model we built in this study could provide skillful deterministic sub-seasonal precipitation forecasts over southeastern and southwestern hydroclimatic regions at a lead time of 20-25 days. However, the deterministic forecast skills are much lower over northeastern China, owing to the underestimation of intraseasonal variability in these regions. The probabilistic forecasts are more promising, and the results indicate that the Bayesian hierarchical model could provide skillful and reliable sub-seasonal precipitation forecasts for all hydroclimatic regions from 0-day to 25-day leads. Other sources of sub-seasonal predictability would be included in the future to further improve sub-seasonal precipitation forecast skills. 
https://doi.org/10.5194/hess-2022-67

\section{Introduction}

Accurate and reliable sub-seasonal precipitation forecasts can provide vital information for many management decisions in water resources, agriculture, and disaster mitigations (Vitart et al., 2012; Vitart and Robertson, 2018). One approach for sub-seasonal precipitation forecasts is to run dynamical models such as Global Climate Models (GCMs). Projects such as the Subseasonal-to-Seasonal Prediction Project (S2S) and the Subseasonal Experiment (SubX) have been lunched to provide sub-seasonal precipitation forecasts with lead time up to 60 days from GCMs (Pegion et al., 2019; Vitart et al., 2017). However, the sub-seasonal precipitation forecasts derived directly from GCMs are of low accuracy as the physical equations are always simplified and small-scale processes could not be well represented in the GCMs (De Andrade et al., 2019). Post-processing is always required to improve the accuracy and reliability of GCM forecasts before it could be used for other applications. Schepen et al. (2018) and our previous study (Li et al., 2020) used the Bayesian Joint Probability (BJP) method to post-process sub-seasonal precipitation forecasts over different regions, and the results suggested that the forecast skills and reliability were improved compared to raw GCM forecasts. Vigaud et al. (2020) proposed a new spatial correction method to improve sub-monthly precipitation forecasts derived from multimodel ensembles. Nevertheless, the results also indicated that the accuracy of post-processed sub-seasonal precipitation forecasts were still limited when the lead time was beyond $10-14$ days.

An alternative approach for sub-seasonal precipitation forecasts is to establish statistical models based on the relationships between precipitation and preceding atmospheric-oceanic indices. Although dynamical models are dominant for short- to medium-term forecasts, statistical models are still found to be useful especially for long-term forecasts (Tuel and Eltahir, 2018; Abbot and Marohasy, 2014; Mekanik et al., 2013; Lü et al., 2011; Kirono et al., 2010). Schepen et al. (2012) suggested that the lagged climate indices were potentially useful for seasonal precipitation forecasts over Australia. Plenty statistical algorithms, such as multiple linear regression or canonical correlation analysis, have been developed for seasonal precipitation forecasts based on the assumption that the seasonal anomalies are caused by slow-varying sea surface temperature, sea ice, snow cover, and other boundary conditions (Hwang et al., 2001; Barnston and Smith, 1996; Eden et al., 2015). Totz et al. (2017) proposed a new cluster-based empirical method to predict winter precipitation anomalies over the European and Mediterranean Regions, which the sea surface temperature, geopotential height, sea level pressure, snow cover extent, and sea ice concentration were included as predictors. A random forest based statistical model, which the predictors were 
identified from the gridded sea surface temperature, was developed to predict central and south Asia seasonal precipitation (Gerlitz et al., 2016).

However, much fewer statistical models have been built and applied for sub-seasonal precipitation forecasts as the sources of sub-seasonal predictability are not yet fully understood at such a time scale. Compared to seasonal precipitation forecasts, the slow-varying boundary forcings may have limited impact on sub-seasonal precipitation as the time scale is too short. The atmospheric intraseasonal oscillation (ISO), which is the dominant mode of subseasonal variability, is one of the leading sources of sub-seasonal predictability (Robertson and Vitart, 2018). The boreal summer intraseasonal oscillation (BSISO) in the tropics, which is also known as Madden-Julian Oscillation (MJO) in winter, is characterized as a slow-moving system with a period of 30-90 days in the tropical atmosphere (Madden and Julian, 1971, 1972; Zhang, 2005; Woolnough, 2019; Wang and Xie, 1997). The circulation anomalies associated with the intraseasonal oscillation (ISO) are identified to have an impact on monsoon activities and heavy rainfall events (Annamalai and Slingo, 2001; Chen et al., 2004). Zhang et al. (2009) found that the rainfall patterns in Southeast China were transited from being enhanced to being suppressed when the MJO center moved from the Indian Ocean to the Western Pacific Ocean. Jia et al. (2011) suggested that the MJO influenced the rainfall patterns in China mainly by modulating the circulation in the subtropics and mid-high latitudes in winter. This suggests that the ISO signals could be potentially used for predicting sub-seasonal precipitation not only in tropical regions but extra-tropical regions as well.

Several statistical models have been built to predict sub-seasonal precipitation based on the relationships between ISO signals and precipitation. Hsu et al. (2015) established a set of spatial-temporal projection models (STPMs) to predict sub-seasonal precipitation at a lead time of 10-30 days over southern China. Their results suggested that the forecast skills were still promising at a 20-25-day lead time. Zhu and Li (2017) predicted sub-seasonal precipitation by constructing STPMs over entire China, and independent forecasts of rainfall anomalies during the period of Olympic Games in 2008 and Shanghai World Expo in 2010 suggested that the STPMs were able to reproduce intraseasonal rainfall patterns at a 20-day lead time. However, we should note that the relationships between ISO signals and precipitation are of high uncertainty for different regions at different lead times. Chen and Wang (2021) suggested that different BSISO events would have distinct impact on monsoon systems. To our best knowledge, the uncertainties of relationships between preceding ISO signals and sub-seasonal precipitation have 
not been fully considered in sub-seasonal precipitation forecasts in previous studies.

There are several ways to address the above challenge. Lepore et al. (2017) established an extended logistic regression model to link the relationship between EI Niño-Southern Oscillation (ENSO) and convective storm (SCS) activity. Sohrabi et al. (2021) coupled the large-scale climate indices with a stochastic weather generator to provide ensemble streamflow forecasts. Compared to the above-mentioned traditional probabilistic model solutions, the Bayes-theorem based statistical models are more flexible and more efficient for assessing multiple sources of uncertainties. Wang et al. (2009) proposed a multivariate normal distribution based Bayesian joint probability (BJP) approach to predict seasonal streamflow over Australia using antecedent streamflow, ENSO indices, and other climate indicators as predictors. Peng et al. (2014) utilized the same BJP approach to predict seasonal precipitation over China using lagged oceanic-atmospheric indices. Another Bayes-theorem based approach, the Bayesian hierarchical model (BHM), has also been developed in recent years (Gelman and Hill, 2006). The BHMs are always constructed with several model layers. The predictand is assumed to follow distribution with unknown parameters in the first layer, and the parameters are linked with the predictors using linear regression models in the second layer. The regression coefficients are given hyperprior distributions with the BHMs. The utility of BHMs has been demonstrated in modelling spatiotemporal variability of hydrological variables in many studies (Renard, 2011; Reza Najafi and Moradkhani, 2013; Bracken et al., 2016; Lima and Lall, 2010; Lima and Lall, 2009; Devineni et al., 2013). The BHMs are also used for seasonal predictions in many fields. Chen et al. (2014) used the BHM to predict summer rainfall and streamflow over the Huai River basin, while Chu and Zhao (2007) developed a BHM model to predict seasonal tropical cyclone activity over the Central North Pacific. However, the BHMs have not been used to predict sub-seasonal precipitation before. In this study, we follow a similar BHM structure proposed by Devineni et al. (2013) to predict sub-seasonal precipitation.

China is located in east Asia, and is frequently influenced by rainstorm and flood disasters during the boreal summer monsoon. Accurate and reliable sub-seasonal precipitation forecasts can provide valuable information for mitigating the risks from rainstorm and flood disasters. However, the origin of intraseasonal precipitation variability is of high complexity owing to the mixed impact of tropical convection, forcing of Tibetan Plateau, and mid-high latitude systems (Zhu and Li, 2017). In this study, we first define potential predictors by analyzing the correlations between preceding ISO signals and precipitation for each hydroclimatic region. In a second step, smaller groups of robust 
https://doi.org/10.5194/hess-2022-67

predictors are selected and the Bayesian hierarchical model is established to predict sub-seasonal precipitation. The model performance for both deterministic and probabilistic forecasts are evaluated through a leave one-yearout cross-validation strategy.

In the following section, the observations, reanalysis dataset, ISO signal extraction, potential predictor selection, Bayesian hierarchical model calibration and evaluation are introduced. The deterministic and probabilistic forecast skills are presented in Sect. 3. Section 4 discusses the forecast skills, possible mechanism, limitations, and future work. Key findings are summarized in Sect. 5.

\section{Data and Methodology}

\subsection{Data}

In this study, China is divided into 17 hydroclimatic regions as suggested by Lang et al. (2014). The southeastern hydroclimatic regions are mostly of temperate and warm/hot summer climate without dry season (Cfb/Cfa), while the northwestern regions are mostly arid with limited precipitation (Bwk, Bsh, Bsk climate types) (Peel et al., 2007) (Figure 1). The observed precipitation is derived from the Multi-Source Weighted-Ensemble Precipitation, version 2 (MSWEP V2) dataset. The MSWEP V2 dataset is of high spatial $\left(0.1^{\circ}\right)$ and temporal (3 hourly) resolution. Compared to other gridded datasets, the MSWEP V2 exhibits more realistic spatial patterns, and higher accuracy over land (Wu et al., 2018; Beck et al., 2019). The $0.1^{\circ}$ gridded precipitation data is area-weighted averaging through 17 hydroclimatic regions over China from May to October. After that, the 3-hourly regional precipiation data is summarized to pentad data to reduce the noise and improve the predictability. 


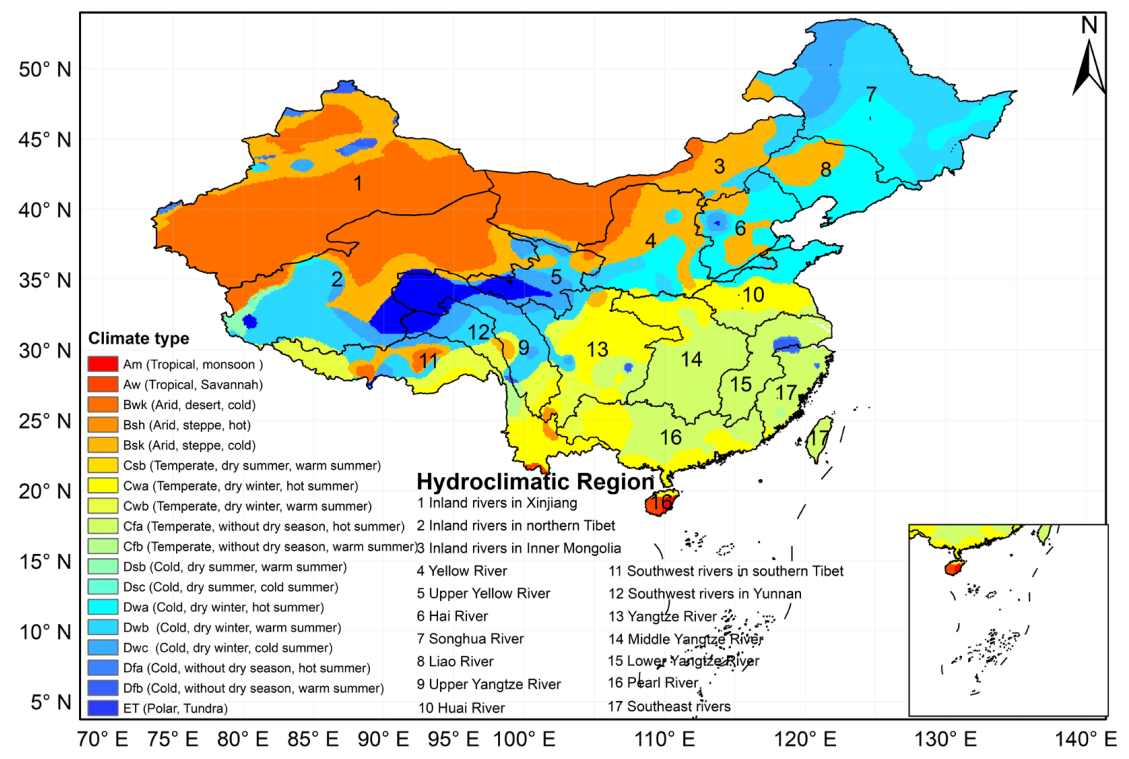

Figure 1. 17 hydroclimatic regions over China.

The intraseasonal oscillation is always represented by outgoing longwave radiation (OLR), zonal winds in the upper $(200 \mathrm{hPa})$ and lower $(850 \mathrm{hPa})$ troposphere. Although several indices, including the RMM (Realtime Multivariate MJO) index (Wheeler and Hendon, 2004) and BSISO index (Lee et al., 2013), have been proposed to monitoring the propagation of oscillation, these indices may not cover patterns which might be important for sub-seasonal precipitation in certain regions. To overcome this problem, we analyze the correlation between regional precipitation and preceding global gridded OLR, zonal wind at $850 \mathrm{hPa}$ (U850), zonal wind at $200 \mathrm{hPa}$ (U200) for each grid cell. In addition, the geopotential height at $850 \mathrm{hPa}, 500 \mathrm{hPa}$, and $200 \mathrm{hPa}(\mathrm{H} 850, \mathrm{H} 500, \mathrm{H} 200)$, which have been proved to be capable of reflecting the MJO structure as the zonal wind (Leung and Qian, 2017), are also analyzed. The OLR-daily Climate Data Record (CDR) used in this study is derived from National Climate Data Center (NCDC) on a $1.0^{\circ}$ squared resolution over the globe. The OLR-daily CDR is developed from high resolution infrared radiation sounder instruments, and is valuable to a wide range of applications. A more detailed description of the OLR dataset can be found at https://www.ncdc.noaa.gov/news/new-outgoing-longwave-radiation-climate-data-record. The global gridded daily average U850, U200, $\mathrm{H} 850, \mathrm{H} 500, \mathrm{H} 200$ data are derived from the ERA5 reanalysis dataset at https://cds.climate.copernicus.eu/. The ERA5 reanalysis dataset is produced using advanced 4D-Var data assimilation scheme, and its horizontal resolution is approximately $30 \mathrm{~km}$ with 137 pressure levels in the vertical (Hersbach et al., 2020). It provides hourly record of global atmosphere, land surface and ocean waves from 1950 
to present. To focus on large-scale features and increase calculating efficiency, both the OLR-daily CDR dataset and the daily average ERA5 reanalysis dataset are bilinearly interpolated onto $2.5^{\circ} \times 2.5^{\circ}$ latitude-longitude resolution. Moreover, we choose to focus on the period of 1979-2016 to be consistent with the temporal coverage of observed precipitation data.

\subsection{Methodology}

\subsubsection{0-60-day ISO signal extraction}

As briefly introduced in previous section, extracting meaningful ISO signals is important for sub-seasonal precipitation forecasts. However, the high-frequency (unpredictable) noises exist for both raw daily precipitation data and raw daily large-scale circulation variables. Band-pass filtering methods, such as the fast Fourier transformation, should be used to isolate intraseasonal low-frequency (10-60-day) signals from raw data (Zhang, 2005). However, traditional band-pass filtering method is impractical for real time applications as future information beyond the current date is needed. In this study, a non-filtering method proposed by Hsu et al. (2015) is used to extract sub-seasonal component with a period between 10 and 60 days for both the ISO variables and precipitation. Compared to traditional ISO signal extraction method, this approach is easy to implement and could be used for real time applications. The climatological annual cycle of raw daily data is first removed by subtracting 90 -day lowpass filtered climatological component:

$$
x^{\prime}=x-\bar{x}
$$

where $x$ is the areal-weighted daily precipitation data for each hydroclimatic region or the gridded large-scale circulation variable U850, U200, OLR, H850, H500, or H200, $\bar{x}$ is the corresponding climatological 90-day lowpass filtered component derived by Lanczos filtering method for the period of 1981-2010 (Duchon, 1979). In a second step, lower-frequency signals longer than 60 days are removed by subtracting the last 30 -day running mean,

$$
x^{\prime \prime}=x^{\prime}-{\overline{x^{\prime}}}^{30 d}
$$

where $\bar{x}^{30 d}$ is the last 30-day running mean of $x^{\prime}$.

The higher-frequency signals are then removed by taking a pentad mean,

$$
x^{*}={\overline{x^{\prime \prime}}}^{5 d}
$$

The so-derived variables represent the 10-60-day component of ISO signals and precipitation. 
https://doi.org/10.5194/hess-2022-67

\subsubsection{Defining potential predictors}

To identify relevant areas of large-scale circulation fields that could affect $10-60$-day precipitation variability, we analyze the correlation between extracted ISO signals in the preceding six pentads and 10-60-day component of precipitation for each hydroclimatic region during the period of 1979-2016. Owing to the data persistence introduced by the filtering method, the effective degree of freedom for each grid cell and each preceding pentad is estimated following Livezey and Chen (1983). The identified significantly correlated preceding ISO signals are then used to establish the Bayesian hierarchical model to produce a 0-25-day lead time precipitation forecasts.

As an example, Figure 2 presents the correlation between preceding U850, U200, OLR, H850, H500, H200 and 10-60-day component of precipitation over Region 1 (Inland Rivers in Xinjiang) at different lead times. At leads 25 to 20 days, the significantly correlated U850 signals are mainly over the Arabian Sea and the Bay of Bengal. The U850 signals are then propagating eastward toward South China Sea and Philippine Sea at the lead of 15 to 10 days. The U850 anomalies then gradually moved eastward and northward toward West Pacific Ocean, Mongolia plateau, Iranian plateau, and Qinghai-Tibet plateau from the lead of 10 to 0 days. The U200 ISO signals are more pronounced compared to U850 signals. The spatial distribution of potential predictive U200 regions is rather concentrated, indicating more robust statistical relationships. The OLR anomalies appear near the Indian Ocean at 20 to 15 day leads. At lead 5 to 0 day, the significantly correlated OLR signals are mainly over the East European Plain and West Siberian Plain. The H850 and H500 high anomalies appear near the Africa at the lead of 20 days to 15 days, and gradually move eastward and northward toward Indian Ocean, Iranian plateau, and Central Asia from the lead of 10 to 0 days. Unlike the $\mathrm{H} 850$ and $\mathrm{H} 500$ fields that originated over the Africa, the $\mathrm{H} 200$ anomaly appears to originate from the Indian Ocean and West Pacific Ocean from leads of 25 to 15 days. At lead 10 to 0 days, the significantly correlated H200 signals are mainly over the East European Plain, West Siberian Plain, and Central Siberian plateau.

To avoid defining too many predictors, which would lead to overfitting, we define potential predictors by averaging U850, U200, OLR, H850, H500, H200 signals in the areas of significant correlations at different lead times. The irregular boundaries of significant correlated areas are identified by the Python package scikit-image (Walt et al., 2014). A total number of about one or two dozen potential predictors are defined for each hydroclimatic region and each preceding pentad. 
https://doi.org/10.5194/hess-2022-67

Hydrology and

Preprint. Discussion started: 3 March 2022

(c) Author(s) 2022. CC BY 4.0 License.

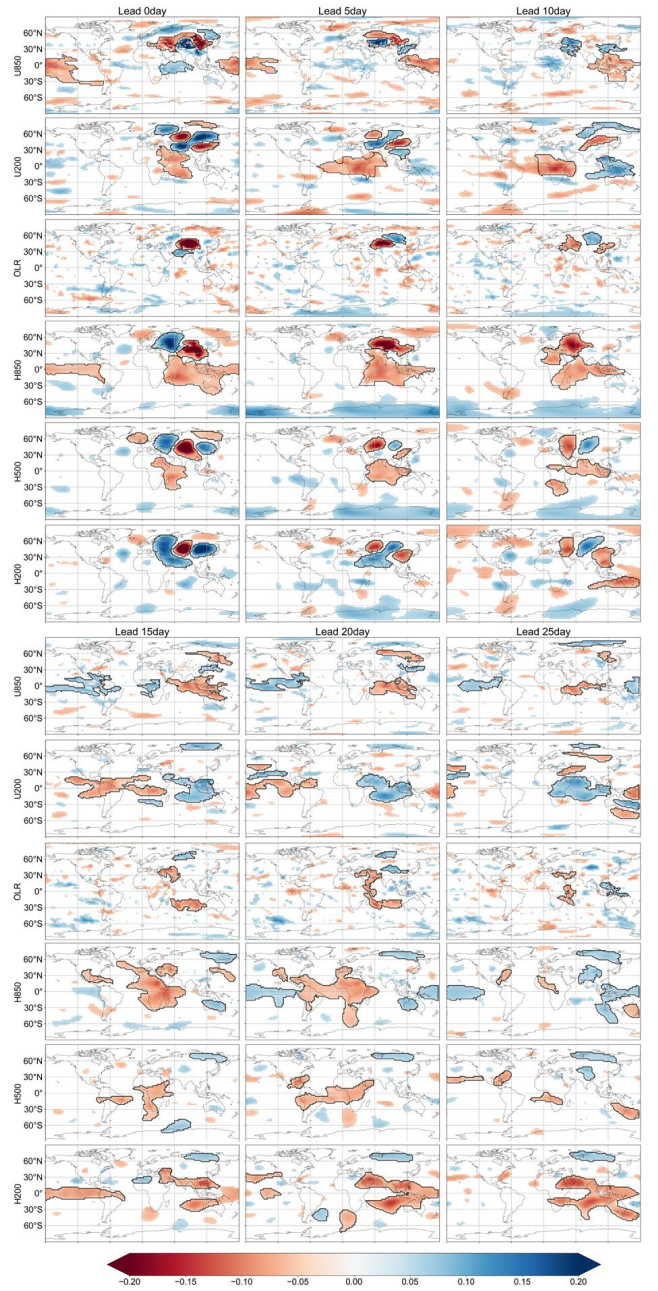

Figure 2. Correlation between preceding ISO signals of U850, U200, OLR, H850, H500, H200 and 10-60-day component of precipitation over Region 1 (Inland Rivers in Xinjiang) at different lead times. Correlation coefficients statistically significant at the $5 \%$ level are shaded.

\subsubsection{Statistical modelling}

In previous steps, we defined potential predictors by analyzing the relationship between ISO signals and 10-60day component of precipitation. The so-derived predictors could be used to predict sub-seasonal precipitation amount as well as precipitation indices (Li et al., 2016; Leung and Qian, 2017). Here, the defined predictors are 
used to predict pentad mean precipitation amount as it could also be used for hydrological applications. Consider, for example, predicting pentad mean precipitation for the period between $1^{\text {th }}$ May and $5^{\text {th }}$ May, 1979 . In this case, ISO signals extracted on $30^{\text {th }}$ April, $25^{\text {th }}$ April, $20^{\text {th }}$ April, $15^{\text {th }}$ April, $10^{\text {th }}$ April, $5^{\text {th }}$ April 1979 are used as predictors to produce precipitation forecasts at different lead times. A leave-one-year-out cross-validation strategy is implemented for both potential predictor selection, normalization, model building, and verification to avoid any bias in skill (Michaelsen, 1987). For instance, to produce sub-seasonal precipitation forecasts in 1979, the predictors (preceding ISO signals) and predictand (pentad mean precipitation) during the period of 1980-2016 are pooled together for statistical modelling. The forecasts for the year 1979 are then issued by models trained on 1980-2016, and the performance is evaluated against the observations. This cross-validation strategy ensures that the data used for evaluation is never used for statistical modelling.

\section{Potential predictor selection}

The number of potential predictors defined previously is still too large for statistical modelling. To narrow down the number of potential predictors, we first use the Least Absolute Shrinkage and Selection Operator (LASSO) regression to select a smaller subset of robust potential predictors. LASSO is a regularization method that reduces the absolute value of large coefficients. It has been proved to be efficient in selecting predictors and reducing model complexity in many fields (Hammami et al., 2012; Chu et al., 2020). A detailed description of LASSO could be found in (Nardi and Rinaldo, 2011; Mcneish, 2015). After that, we utilize a combined forward and backward variable selection process, which is also known as the stepwise regression, to further select the most informative predictors for each hydroclimatic region and each preceding pentad.

\section{Bayesian hierarchical model framework}

Before establishing the Bayesian hierarchical model, we standardize and normalize the pentad mean precipitation data $Y_{s, t}$ over Region $s$ at the lead time of $t$ to $V_{s, t}$ using the log-sinh transformation method proposed by Wang et al. (2012). The zero values of pentad mean precipitation are treated as censored data. The selected preceding potential predictors $\boldsymbol{X}_{s, t}^{T}=\left[X_{1, s, t} X_{2, s, t} \cdots X_{n, s, t}\right]$ are standardized and normalized to $\boldsymbol{U}_{s, t}^{T}=\left[U_{1, s, t} U_{2, s, t} \cdots U_{n, s, t}\right]$ through the Yeo-Johnson transformation method as the input variables are allowed to be negative (Yeo and Johnson, 2000). The normalization parameters are estimated using the SCE-UA (shuffled complex evolution method developed at The University of Arizona) method that maximize the log-likelihood function. A more detailed 
There are many versions and variations of BHMs. In this study ,we establish the BHM model following Devineni et al. (2013) and Chen et al. (2014). However, the spatial correlation of precipitation over different regions is not considered here. A traditional no-pooling BHM is built for each hydroclimatic region separately. Meanwhile, the potential predictors have been selected using the LASSO and stepwise regression previously. This indicates that the predictors used for establishing the BHM are independent. Thus, it is reasonable to model the related regression coefficients in the BHM independently. The transformed pentad mean precipitation $V_{s, t}$ is assumed to follow the normal distribution,

$$
V_{s, t} \sim N\left(\mu_{s, t}, \sigma_{s, t}^{2}\right)
$$

We then link the parameter $\mu_{s, t}$ with the normalized predictors using a linear model,

$$
\mu_{s, t}=\beta_{0, s, t}+\sum_{i=1}^{n} \beta_{i, s, t} U_{i, s, t}
$$

where $\beta_{i, s, t}$ is the slope term for Region $s$ at the lead time of $t$ corresponding to the predictor $U_{i, s, t}$. This indicates that the regression coefficients are modeled independently.

To complete the hierarchical formulation, we assume the unknown parameters, including $\sigma_{s, t}, \beta_{0, s, t}, \cdots, \beta_{n, s, t}$, follow non-informative priors:

$$
\begin{gathered}
\frac{1}{\sigma_{s, t}^{2}} \sim \mathrm{U}(0,100) \\
\beta_{i, s, t} \sim N\left(0,10^{4}\right), \quad i=0, \cdots, n
\end{gathered}
$$

This implies that the information used for posterior distribution inference is only provided by the data.

Given $\boldsymbol{\theta}=\left\{\left(\sigma_{s, t}, \beta_{i, s, t}\right), i=0, \cdots, n\right\}$ denotes parameters in the Bayesian hierarchical model for Region $s$ at the lead time $t, V$ denotes the normalized pentad mean precipitation data, and $\boldsymbol{U}$ denotes the normalized preceding predictors, the full posterior of the parameters is given as:

$$
p(\boldsymbol{\theta} \mid \boldsymbol{U}, V) \propto p(V \mid \boldsymbol{\theta}, \boldsymbol{U}) p(\boldsymbol{\theta})
$$

where $p(V \mid \boldsymbol{\theta}, \boldsymbol{U})$ is the likelihood, and $p(\boldsymbol{\theta})$ is the prior of parameters $\boldsymbol{\theta}$. As the posterior distributions of parameters $\boldsymbol{\theta}$ are not standard distributions, it is difficult to conduct analytical integration. In this study, we use the R package runjags (Denwood, 2016) to calibrate the parameters of the BHM. The runjags offers an interface to facilitate calibrating BHMs employ a Gibbs sampling algorithm in Just Another Gibbs sampler (JAGS). The initial 
values of model parameters $\boldsymbol{\theta}$ are first randomly sampled from prior distributions. The parameters $\boldsymbol{\theta}$ are then updated based on the full conditional distributions. We use five independent Markov chains in each model run, with a total number of 10,000 iterations for each chain. The convergence is ensured by the potential scale reduction factor $\hat{R}$ (Brooks and Gelman, 1998). An approximate convergence is diagnosed when the $\hat{R}$ is less than 1.1 for all parameters.

Once the parameters are sampled, the Bayesian hierarchical model can be used to forecast sub-seasonal precipitation using preceding large-scale circulation signals. Given new preceding predictors $\boldsymbol{X}_{s, t}^{*}=\left[X_{1, s, t}^{*} \cdots X_{n, s, t}^{*}\right]^{T}$ at the lead time of $t$, the normalized predictors $\boldsymbol{U}_{s, t}^{*}=\left[U_{1, s, t}^{*} \cdots U_{n, s, t}^{*}\right]^{T}$ are found using the estimated transformation parameters during the training period. The posterior predictive distribution of normalized pentad mean precipitation is given as:

$$
\begin{gathered}
V_{s, t}^{*} \sim N\left(\mu_{s, t}^{*}, \sigma_{s, t}^{2}\right) \\
\mu_{s, t}^{*}=\beta_{0, s, t}+\sum_{i=1}^{n} \beta_{i, s, t} U_{i, s, t}^{*}
\end{gathered}
$$

Again, the Gibbs sampling algorithm is used to obtain samples of $V_{s, t}^{*}$ by given parameter value sets $\theta$. The samples of $V_{s, t}^{*}$ are then back-transformed to produce ensemble precipitation forecasts of $Y_{s, t}^{*}$ over Region $s$ at the lead time of $t$.

\subsubsection{Deterministic and Probabilistic Evaluation}

The deterministic sub-seasonal precipitation forecast skills are evaluated using the Kling-Gupta Efficiency (KGE):

$$
\begin{gathered}
\mathrm{KGE}=1-\sqrt{(r-1)^{2}+(\beta-1)^{2}+(\gamma-1)^{2}} \\
r=\frac{\sum_{i=1}^{N}\left(y_{i}-\bar{y}\right)\left(o_{i}-\bar{o}\right)}{\sqrt{\sum_{i=1}^{N}\left(y_{i}-\bar{y}\right)^{2}} \sqrt{\sum_{i=1}^{N}\left(o_{i}-\bar{o}\right)^{2}}} \\
\beta=\frac{\mu_{y}}{\mu_{o}} \\
\gamma=\frac{\sigma_{y}}{\sigma_{o}}
\end{gathered}
$$

where $y_{i}$ is the ensemble mean forecasts for case $i, i=1,2, \cdots, N ; o_{i}$ is the corresponding observation. $\mu_{y}$ is the forecast mean for all cases; while $\mu_{o}$ is the observation mean for all cases. $\sigma_{f}$ is the standard deviation in ensemble mean forecasts; while $\sigma_{o}$ is the standard deviation in observations. $r$ represents the correlation coefficient between ensemble mean forecasts and the observations, $\beta$ represents the forecast bias, and $\gamma$ measures the variability error. Compared with other evaluation metrics, the KGE offers an insight into the model performance as the decomposition into correlation, bias, and variability term. A full discussion of the KGE-statistics 
sees Gupta et al. (2009) and Kling et al. (2012). The KGE ranges from negative infinity to one. A value of one suggests that the ensemble mean forecasts are the same as the observations.

The Continuous Ranked Probability Score (CRPS) is used to provide an overall evaluation of the accuracy of probabilistic sub-seasonal precipitation forecasts:

$$
\mathrm{CRPS}=\frac{1}{N} \sum_{i=1}^{N} \int\left[F_{i}(y)-H\left(y-o_{i}\right)\right]^{2} d y
$$

where $F_{i}()$ is the cumulative distribution function of the ensemble forecasts for case $i$; and $H()$ is the Heaviside step function defined as:

$$
H\left(y-o_{i}\right)= \begin{cases}0 & y<o_{i} \\ 1 & \mathrm{y} \geq o_{i}\end{cases}
$$

where $o_{i}$ is the corresponding observation.

The CRPS skill score is then calculated by comparing the CRPS of ensemble forecasts with the CRPS of reference forecasts:

$$
\mathrm{CRPS}_{\mathrm{SS}}=\frac{\mathrm{CRPS}_{\mathrm{REF}}-\mathrm{CRPS}}{\mathrm{CRPS}_{\mathrm{REF}}} \times 100 \%
$$

The reference forecasts are generated using the Bayesian hierarchical model with no predictors used for prediction. A skill score of $100 \%$ indicates that the ensemble forecasts are the same as the observations, whereas a skill score of $0 \%$ suggests that the ensemble forecasts show no improvement over the cross-validated climatology. A negative skill score means that the ensemble forecasts are inferior to the cross-validated climatology.

The attribute diagram is used here to evaluate the reliability, resolution, and sharpness of the probabilistic forecasts. The attribute diagram shows the observed frequencies against its forecast probabilities for a given event with binary outcomes (Hsu and Murphy, 1986). In this study, the three class events of below-, near-, and above normal is defined by equally dividing the cross-validated climatology into terciles. The forecast probability is binned as 5 equal-width intervals. The corresponding observed relative frequency is plotted against the mean forecast probability in each bin. The forecasts are reliable if the scatters are along the 45-degree diagonal. The sharpness is also shown on the attribute diagram. The forecasts are sharp if the probabilities tend to be either very high (e.g. > $90 \%$ ) or very low (e.g. $<10 \%)$ (Peng et al., 2014). The sharpness is indicated by the size of dots in each bin. The 
attribute diagram requires a large number of samples to draw robust conclusions. In this study, the probabilistic forecasts over the 17 hydroclimatic regions are pooled together to increase the sample size for each lead time.

\section{Results}

\subsection{Deterministic forecast skill}

Figure 3 summaries the KGE values for all regions and all lead times. Skillful deterministic sub-seasonal precipitation forecasts are observed mainly in regions in southeastern and southwestern China. The KGE values are above 0.2 over Region 2 (Inland Rivers in northern Tibet), Region 9 (Upper Yangtze River), Region 11 (Southwest Rivers in Southern Tibet), Region 12 (Southwest Rivers in Yunnan), Region 13 (Yangtze River), and Region 16 (Pearl River) for almost all lead times. Although the KGE values are lower in Region 1 (Inland Rivers in Xinjiang), Region 7 (Songhua River), Region 14 (Middle Yangtze River), Region 15 (Lower Yangtze River), and Region 17 (Southeast Rivers), positive KGE values still can be found when the lead time is beyond 10 days. This indicates that the deterministic forecasts still can provide useful in formation at longer lead times over these regions. Much lower predictive skills are observed in northern and northeastern regions, that is Region 3 (Inland Rivers in Inner Mongolia), Region 4 (Yellow River), Region 5 (Upper Yellow River), Region 6 (Hai River), Region 8 (Liao River), and Region 10 (Huai River). The KGE values over these regions are near or below zero when the lead time is beyond 5 days.

Figure 4 shows the ensemble mean forecasts during the period of $1979 \sim 2016$, alongside $50 \%$ and $95 \%$ confidence intervals from the Bayesian hierarchical model over Region 1 (Inland Rivers in Xinjiang) at different lead times. The positive KGE values suggest that the established Bayesian hierarchical model can provide skillful deterministic ensemble mean forecasts. 
https://doi.org/10.5194/hess-2022-67

Preprint. Discussion started: 3 March 2022

(c) Author(s) 2022. CC BY 4.0 License.
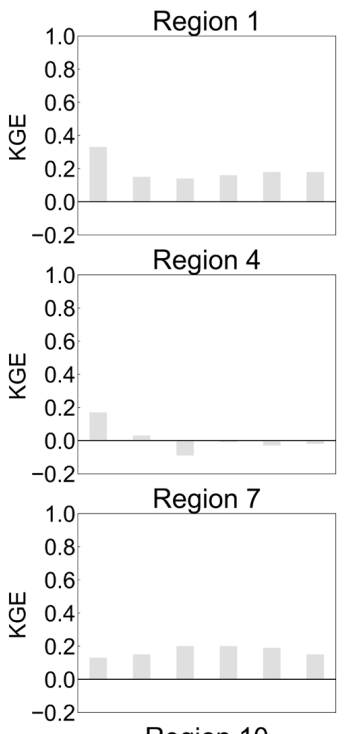

Region 10
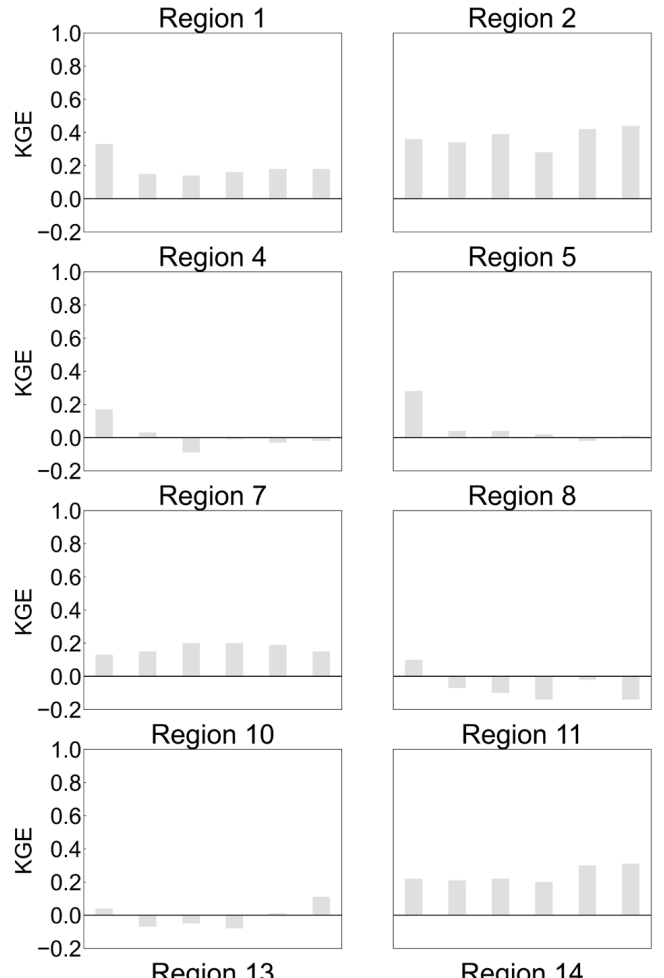

Region 5

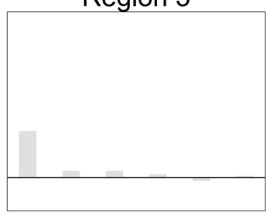

Region 8

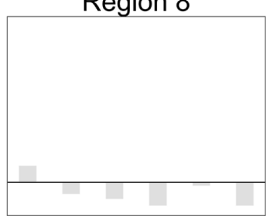

Region 11

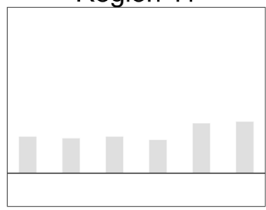

Region 14
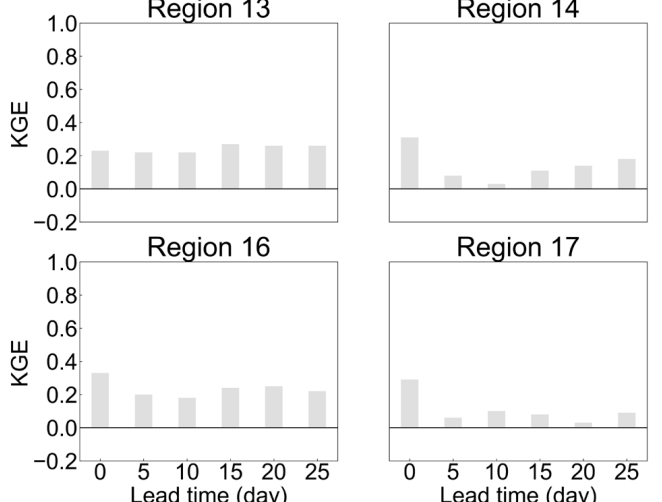

Region 17

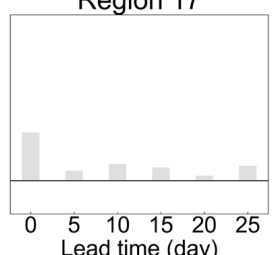

Region 3

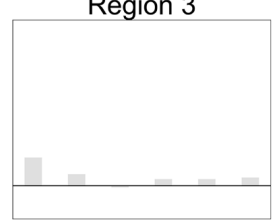

Region 6

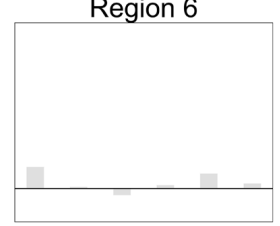

Region 9

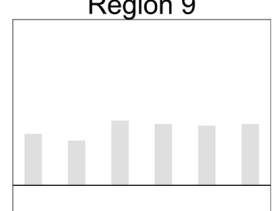

Region 12

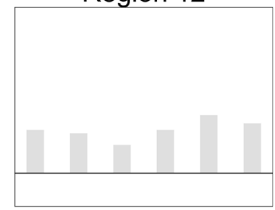

Region 15

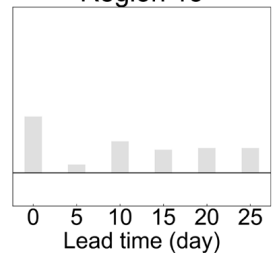

Figure 3. Kling-Gupta Efficiency of Pentad mean precipitation forecasts at different lead times over 17 hydroclimatic regions during the boreal summer monsoon. 
https://doi.org/10.5194/hess-2022-67

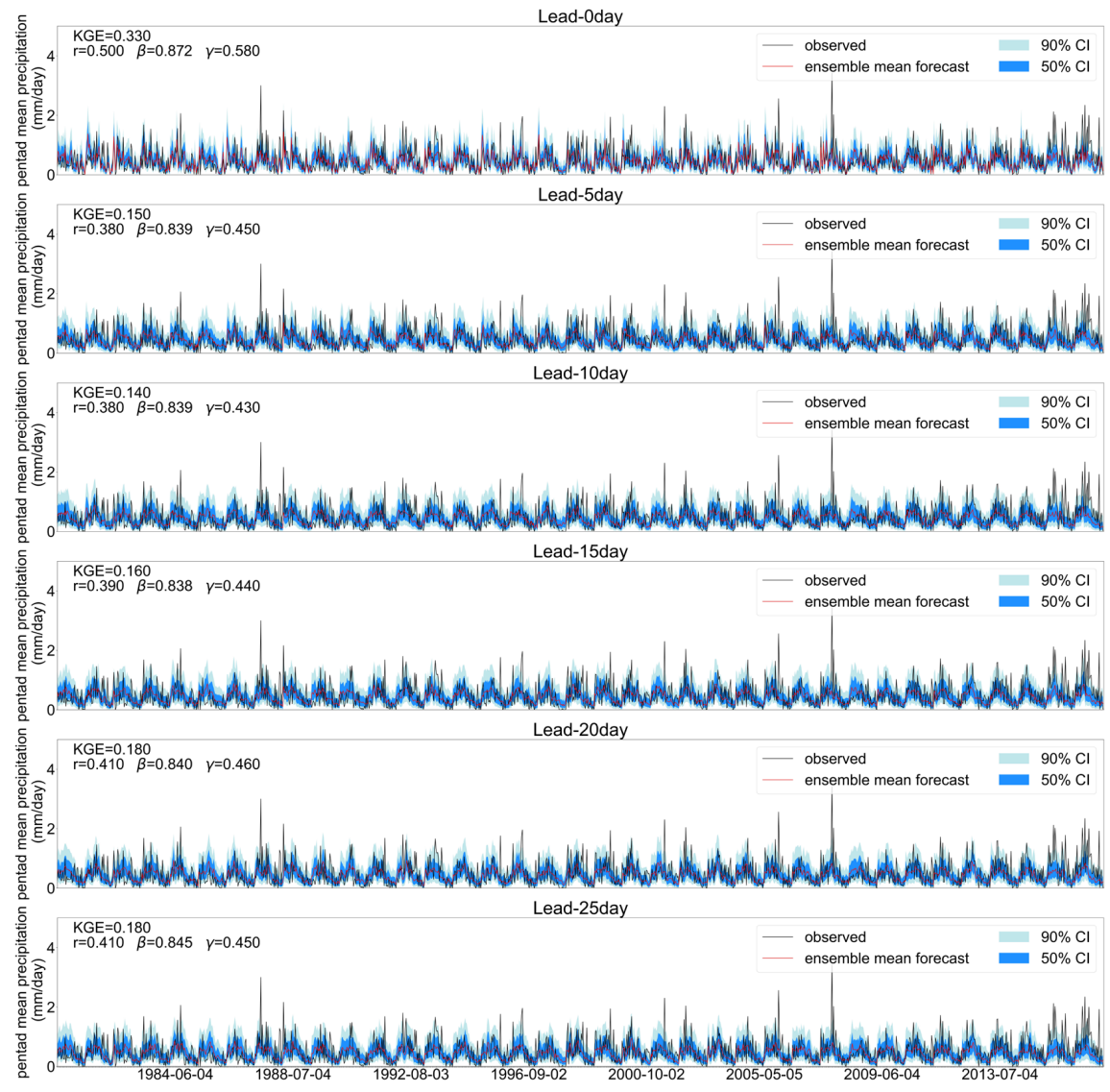

Figure 4. Pentad mean precipitation forecasts at different lead times over Region 1 (Inland Rivers in Xinjiang) during the boreal summer monsoon from 1979 to 2016. The ensemble mean forecasts are shown by the red line, observations by the black line, alongside $50 \%$ (shaded in blue) and $95 \%$ (shaded in powderblue) confidence intervals. $\mathrm{Cl}=$ confidence interval.

\subsection{Probabilistic forecast skill}

The positive CRPS skill scores shown in Figure 5 suggest that the Bayesian hierarchical model is able to provide skillful probabilistic forecasts for all regions and all lead times. The CRPS skill scores are mostly over $10 \%$ over regions where positive KGE values are observed, including Region 2 (Inland Rivers in northern Tibet), Region 9 (Upper Yangtze River), Region 11 (Southwest Rivers in Southern Tibet), Region 12 (Southwest Rivers in Yunnan), Region 13 (Yangtze River), and Region 16 (Pearl River). Although the KGE values are negative over Region 3 
https://doi.org/10.5194/hess-2022-67

(Inland Rivers in Inner Mongolia), Region 4 (Yellow River), Region 5 (Upper Yellow River), Region 6 (Hai River), Region 8 (Liao River), and Region 10 (Huai River) when the lead time is beyond 5 days, the positive CRPS skill scores suggest that the probabilistic forecasts still can provide valuable information compared to climatological forecasts at longer lead times.
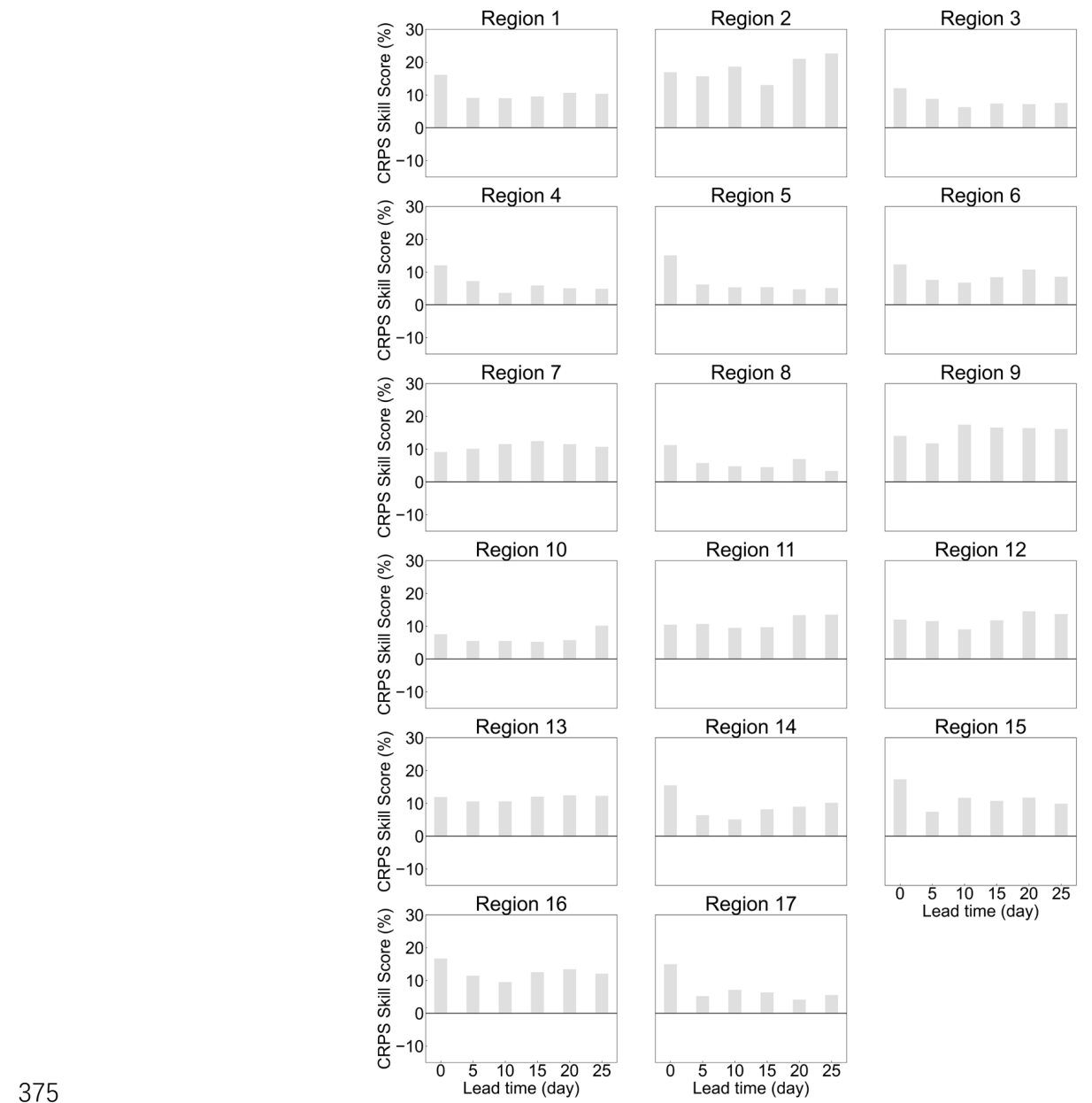

Region 11
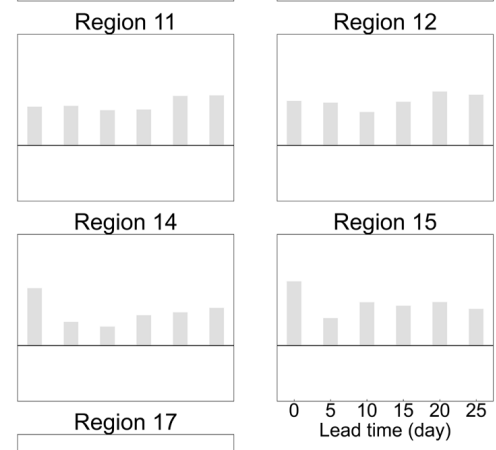

Figure 5. Continuous Ranked Probability Skill Score of Pentad mean precipitation forecasts at different lead times over 17 hydroclimatic regions during the boreal summer monsoon.

Attribute diagrams of the sub-seasonal precipitation probabilistic forecasts at different lead times are shown in Figure 6. Most points fall near the 1:1 line for all events and all lead times, indicating that the probabilistic forecast distributions are reliable. The results also suggest that the probabilistic forecasts are sharp at all lead times, 
https://doi.org/10.5194/hess-2022-67

Hydrology and

Preprint. Discussion started: 3 March 2022

(c) Author(s) 2022. CC BY 4.0 License.

especially for below-normal and above normal categories.
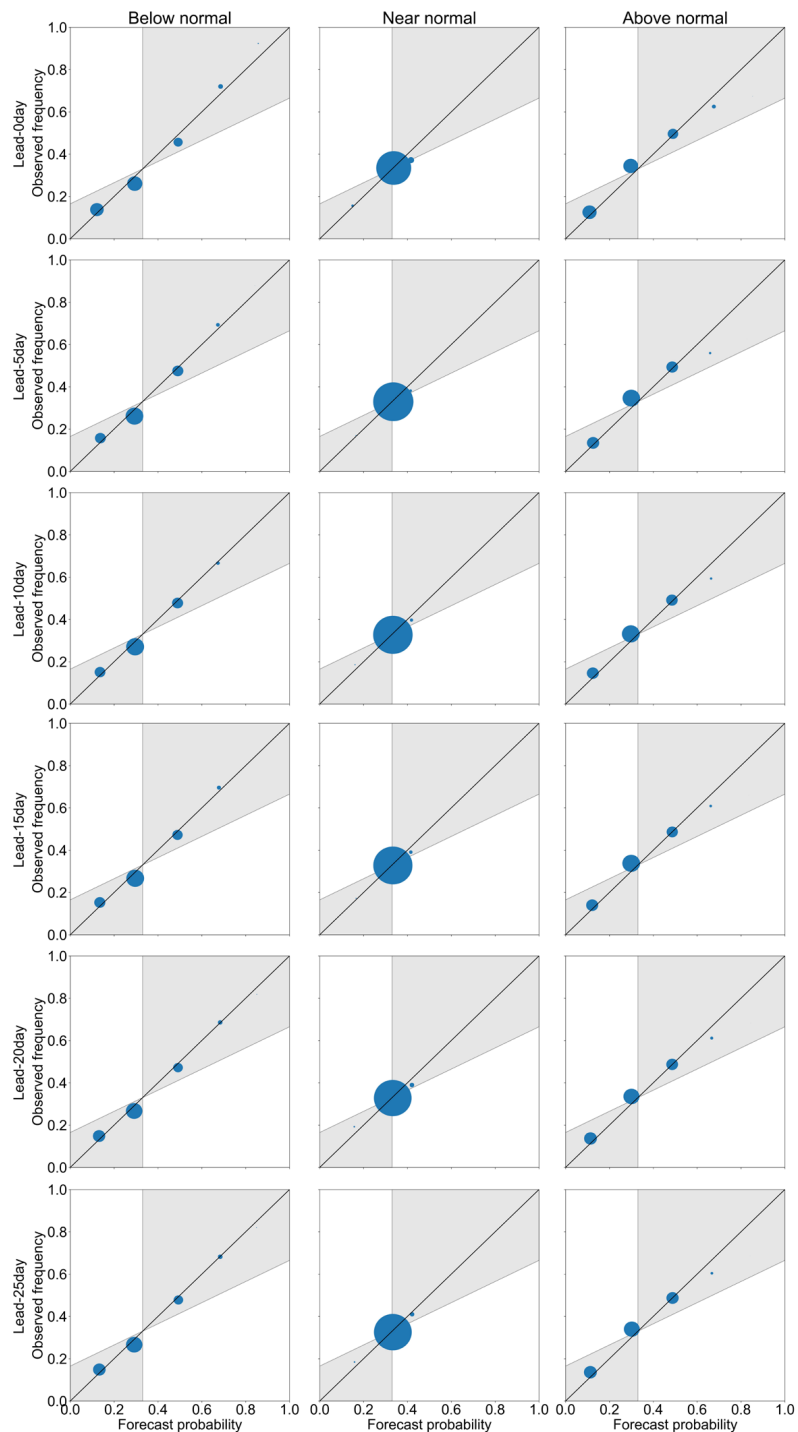

Figure 6. Attribute diagram of pentad mean precipitation forecasts during the boreal summer monsoon for tercile of probabilistic forecasts. 


\section{Discussion}

\subsection{Forecast skill and possible mechanism}

In this study, we first define potential predictors by analyzing the relations between pentad mean precipitation and preceding 10-60-day ISO large-scale circulation signals. Robust predictors are identified using the Lasso regression and stepwise regression approaches. A Bayesian hierarchical model is then established to predict subseasonal precipitation for each hydroclimatic region. Our results demonstrate that the Bayesian hierarchical model could provide skillful deterministic sub-seasonal precipitation forecasts over southeastern and southwestern hydroclimatic regions in China. However, the deterministic predictive skills over northeastern China are much lower. The decomposition of KGE values suggest that the intraseasonal variability is underestimated in these regions. This may be explained by the different characteristics of intraseasonal variability and different possible mechanism over different hydroclimatic regions. Wang (2007) analyzed the precipitation variability from April to September over China, and the results suggested that the seasonal component accounted for nearly $70 \%$ of the total variability over northeastern China. The intraseasonal (10-90 days) component only accounted for nearly $7 \%$ of the total variability, which indicate that the intraseasonal precipitation over these regions have no significant frequency peak. In comparison, the sub-seasonal component accounted for over $20 \%$ of the total variability in southeastern and southwestern China. Ouyang and Liu (2020) also found that the boreal summer monsoon intraseasonal variability of precipitation over the lower Yangtze River basin was mainly dominated by the relatively low-frequency 12-20day variability and high-frequency 8-12-day variability. Wang and Duan (2015) demonstrated that the Quasibiweekly oscillation (QBWO, 10-20 days oscillation) was the dominant mode of intraseasonal variability of summer precipitation over the Tibetan Plateau. The relations between atmospheric intraseasonal oscillation and the lowfrequency variability of precipitation vary from region to region as well. Ren and Shen (2016) suggested that the impact of tropical atmospheric intraseasonal oscillation on precipitation were more significant in regions in southern China and the Tibetan Plateau areas during the boreal summer.

Compared to deterministic forecasts, the probabilistic forecasts are more promising, especially at longer lead times. The CRPS skill scores are over $10 \%$ in southeastern and southwestern China when the lead time is beyond 10 days. The skill scores still reach a value of over $5 \%$ in other hydroclimatic regions. In contrast, the CRPS skill scores of the BJP calibrated sub-seasonal precipitation forecasts were almost $0 \%$ at the lead time of $10-30$ days ( $\mathrm{Li}$ et al., 2020). This suggests that the Bayesian hierarchical model could provide useful forecast information at longer lead 
times when preceding ISO signals are used as predictors. However, we should also note that the highest CRPS skill scores of the Bayesian hierarchical model are lower than $30 \%$ when the lead time is between $0-10$ days, while that of the calibrated forecasts are over $50 \%$. This indicates that the calibrated forecasts are more skillful for short to medium range precipitation forecasts. The Calibration, Bridging, and Merging (CBaM) method, which makes the best use of GCM outputs, has been proved to be efficient for improving seasonal precipitation over many regions (Strazzo et al., 2019; Schepen and Wang, 2013; Peng et al., 2014). Recently, Specq and Batté (2020) proposed a similar statistical-dynamical approach to improve sub-seasonal precipitation forecasts over the southwest tropical Pacific. In the future, the statistical forecasts generated from lagged atmospheric indices should be included in the calibrated forecasts to further improve sub-seasonal precipitation forecast skills.

\subsection{Limitations and future work}

In this study, the potential predictors are identified using the whole record in spite of the cross-validation strategy used for statistical modelling. This may introduce artificial skill into the models to some extent. However, defining potential predictors for each step of the cross-validation is difficult in practice. The potential predictors were defined by averaging signals in the areas of significant correlations with large extent for each hydroclimatic region and lead time in this study. Nevertheless, this procedure was time consuming. Although we identified the irregular boundaries of significant correlated areas automatically by the Python package scikit-image (Walt et al., 2014), we should note the correlation did not equal causation. We carefully selected potential predictors by analyzing the possible mechanism of sub-seasonal precipitation for each hydroclimatic region and each lead time. In addition, the definition of potential predictors for each step of the cross-validation is likely to yield similar results. Here, we analyzed the spatial patterns of correlations between lagged signals and filtered precipitation over Region 1 at the lead time of 0-day for each step of the leave-one-year out cross-validation. The results showed little variability compared to the correlation patterns shown in Figure 2. The cross-validation strategy used in the statistical modelling procedure could also reduce the chance of overfitting (Vehtari and Lampinen, 2002; Delsole and Shukla, 2009).

Another limitation of this study is the treatment of zero values adopted in the statistical modelling procedure. We treated the zero values as censored data, which was also referred as "explicit" approach in Mcinerney et al. (2019). Although this treatment performed well in "low-ephemeral" and "mid-ephemeral" catchments, the performance of 
this "explicit" approach was poor in "high-ephemeral" (> 50\% zero flows) catchments. Further development is required to overcome this problem. The copula functions are flexible in choosing marginal distributions, and have been widely used in hydrological simulations in recent years (Zhang and Singh, 2007; Vernieuwe et al., 2015; De Michele and Salvadori, 2003). Compared to the Bayesian statistics we used in this study, the copula functions are more general and the normalization may not be required when the skewed distributions are used as the marginal distribution of precipitation. This may provide a possible solution to overcome the problems caused by the large amount of zero values.

We built the Bayesian hierarchical model for each hydroclimatic region separately. However, the spatial patterns of precipitation have not been considered yet. The spatial Bayesian hierarchical model, which is able to capture the spatial dependence of precipitation between different regions, could be used to provide sub-seasonal precipitation forecasts with spatial coherence (Reza Najafi and Moradkhani, 2013; Bracken et al., 2016). An alternative way to reconstruct the spatial patterns of probabilistic precipitation forecasts is to use the Schaake Shuffle method or Ensemble Copula Coupling method (Roman et al., 2013; Clark et al., 2004). Higher spatial or temporal resolution of precipitation forecasts are also needed for sub-seasonal streamflow forecasts. However, our previous studies indicated that post-processed daily precipitation forecasts from GCMs are of low accuracy when the lead time is beyond 10-14 days. In this study, the large-scale ISO signals was only used to predict pentad mean precipitation as the daily precipitation noise was too large. Spatial or temporal disaggregation may be required in the future to provide daily precipitation forecasts as inputs for hydrological models.

\section{Conclusions}

Sub-seasonal precipitation forecasts are difficult as the predictability from atmospheric initialization is lost after two weeks, while the slowly varying boundary conditions do not have substantial impact at such a time scale. The intraseasonal oscillation (ISO) is considered as one of the leading sources of sub-seasonal predictability. However, the relationships between ISO signals and precipitation are of high uncertainty. In this study, we first defined potential predictors by analyzing the correlations between preceding ISO signals and precipitation for each hydroclimatic region and each lead time. The LASSO and stepwise regression approaches were used to narrow down the number of potential predictors. A Bayesian hierarchical model was then established to predict subseasonal precipitation during the boreal summer monsoon season. The model performance was evaluated through 
https://doi.org/10.5194/hess-2022-67

a leave one-year out cross-validation strategy for both deterministic and probabilistic forecasts.

Our results suggested that the statistical model we built in this study could provide skillful deterministic subseasonal precipitation forecasts over southeastern and southwestern hydroclimatic regions at a lead time of 20-25 days. However, the deterministic forecast skills are much lower over northeastern China, partly owing to the underestimation of intraseasonal variability in these regions. The probabilistic forecasts are more promising, especially at longer lead times. The skill scores and attribute diagrams demonstrated that the statistical model was able to provide skillful and reliable sub-seasonal precipitation forecasts for all hydroclimatic regions from 0-day to 25-day leads compared to climatological forecasts. This suggests that the probabilistic forecasts still could provide useful information by addressing the uncertainties of relationships between ISO signals and precipitation at subseasonal time scales.

In this study, the large-scale circulation ISO signals were extracted from the zonal wind at 850 and $200 \mathrm{hPa}$, Outgoing Longwave Radiation, and the geopotential height at 850, 500, and $200 \mathrm{hPa}$. Other sources of subseasonal predictability, such as soil moisture, snow cover, and stratosphere-troposphere interaction, could be included in the Bayesian hierarchical model to further improve sub-seasonal precipitation forecasts. The Calibration, Bridging, and Merging ( $\mathrm{CBaM})$ method could also be investigated at sub-seasonal time scale to further improve the forecast skills (Schepen and Wang, 2013; Schepen et al., 2014).

\section{Data availability}

The precipitation dataset used in this study can be derived from http://www.gloh20.org/mswep/. The outgoing Longwave radiation (OLR) dataset can be found at https://www.ncdc.noaa.gov/news/new-outgoing-longwaveradiation-climate-data-record, and the ERA5 dataset can be sourced from https://cds.climate.copernicus.eu/.

\section{Author contribution}

Y.L. and Z.Y. WU designed the experiments and Y.L. carried them out. H.H preprared the data, and H.Y. developed the model code and performed the simulations. Y.L. prepared the manuscript with contributions from all co-authors. 
https://doi.org/10.5194/hess-2022-67

Preprint. Discussion started: 3 March 2022

(C) Author(s) 2022. CC BY 4.0 License.

\section{Competing interests}

The authors declare that they have no conflict of interest.

505

\section{Acknowledgements}

This work was funded by the National Natural Science Foundation of China (Grant number 52009027), the

Fundamental Research Funds for the Central Universities (Grant number 2019B10214). 


\section{References}

Abbot, J. and Marohasy, J.: Input selection and optimisation for monthly rainfall forecasting in Queensland, Australia, using artificial neural networks, Atmospheric Research, 138, 166-178, 2014.

Annamalai, H. and Slingo, J. M.: Active/break cycles: diagnosis of the intraseasonal variability of the Asian Summer Monsoon, Climate Dynamics, 18, 85-102, 10.1007/s003820100161, 2001.

Barnston, A. G. and Smith, T. M.: Specification and Prediction of Global Surface Temperature and Precipitation from

Global SST Using CCA, Journal of Climate, 9, 2660-2697, 10.1175/15200442(1996)009<2660:SAPOGS>2.0.CO;2, 1996.

Beck, H. E., Wood, E. F., Pan, M., Fisher, C. K., Miralles, D. G., van Dijk, A. I. J. M., McVicar, T. R., and Adler, R. F.: MSWEP V2 Global 3-Hourly 0.1? Precipitation: Methodology and Quantitative Assessment, Bulletin of the American Meteorological Society, 100, 473-500, 10.1175/BAMS-D-17-0138.1, 2019.

Bracken, C., Rajagopalan, B., Cheng, L., Kleiber, W., and Gangopadhyay, S.: Spatial Bayesian hierarchical modeling of precipitation extremes over a large domain, Water Resources Research, 52, 6643-6655, https://doi.org/10.1002/2016WR018768, 2016.

Brooks, S. P. and Gelman, A.: General methods for monitoring convergence of iterative simulations, Journal of computational and graphical statistics, 7, 434-455, 1998.

Chen, G. and Wang, B.: Diversity of the Boreal Summer Intraseasonal Oscillation, Journal of Geophysical Research: Atmospheres, 126, e2020JD034137, https://doi.org/10.1029/2020JD034137, 2021.

Chen, T.-C., Wang, S.-Y., Huang, W.-R., and Yen, M.-C.: Variation of the East Asian Summer Monsoon Rainfall, Journal of Climate, 17, 744-762, 10.1175/1520-0442(2004)017<0744:VOTEAS>2.0.CO;2, 2004.

Chen, X., Hao, Z., Devineni, N., and Lall, U.: Climate information based streamflow and rainfall forecasts for Huai River basin using hierarchical Bayesian modeling, Hydrology and Earth System Sciences, 18, 1539-1548, 2014.

Chu, H., Wei, J., and Wu, W.: Streamflow prediction using LASSO-FCM-DBN approach based on hydrometeorological condition classification, journal of hydrology, 580, 10.1016/J.JHYDROL.2019.124253, 2020.

Chu, P.-S. and Zhao, X.: A Bayesian Regression Approach for Predicting Seasonal Tropical Cyclone Activity over the Central North Pacific, Journal of Climate, 20, 4002-4013, 10.1175/JCLI4214.1, 2007.

Clark, M., Gangopadhyay, S., Hay, L., Rajagopalan, B., and Wilby, R.: The Schaake Shuffle: A Method for Reconstructing Space?Time Variability in Forecasted Precipitation and Temperature Fields, Journal of Hydrometeorology, 5, 243-262, 10.1175/1525-7541(2004)005<0243:TSSAMF>2.0.CO;2, 2004. 
de Andrade, F. M., Coelho, C. A., and Cavalcanti, I. F.: Global precipitation hindcast quality assessment of the Subseasonal to Seasonal (S2S) prediction project models, Climate dynamics, 52, 5451-5475, 2019.

De Michele, C. and Salvadori, G.: A Generalized Pareto intensity-duration model of storm rainfall exploiting 2Copulas, Journal of Geophysical Research: Atmospheres, 108, https://doi.org/10.1029/2002JD002534, 2003.

DelSole, T. and Shukla, J.: Artificial Skill due to Predictor Screening, Journal of Climate, 22, 331-345, 10.1175/2008JCLI2414.1, 2009.

Denwood, M. J.: runjags: An R Package Providing Interface Utilities, Model Templates, Parallel Computing Methods and Additional Distributions for MCMC Models in JAGS., Journal of Statistical Software, 71, 1-25, 10.18637/jss.v071.i09, 2016.

Devineni, N., Lall, U., Pederson, N., and Cook, E.: A Tree-Ring-Based Reconstruction of Delaware River Basin Streamflow Using Hierarchical Bayesian Regression, Journal of Climate, 26, 4357-4374, 10.1175/JCLI-D-11$00675.1,2013$.

Duchon, C. E.: Lanczos Filtering in One and Two Dimensions, Journal of Applied Meteorology and Climatology, 18, 1016-1022, 10.1175/1520-0450(1979)018<1016:LFIOAT>2.0.CO;2, 1979.

Eden, J. M., van Oldenborgh, G. J., Hawkins, E., and Suckling, E. B.: A global empirical system for probabilistic seasonal climate prediction, Geosci. Model Dev., 8, 3947-3973, 10.5194/gmd-8-3947-2015, 2015.

Gelman, A. and Hill, J.: Data analysis using regression and multilevel/hierarchical models, Cambridge university press2006.

Gerlitz, L., Vorogushyn, S., Apel, H., Gafurov, A., Unger-Shayesteh, K., and Merz, B.: A statistically based seasonal precipitation forecast model with automatic predictor selection and its application to central and south Asia, hydrology and earth system sciences, 20, 4605-4623, 10.5194/HESS-20-4605-2016, 2016.

Gupta, H. V., Kling, H., Yilmaz, K. K., and Martinez, G. F.: Decomposition of the mean squared error and NSE performance criteria: Implications for improving hydrological modelling, Journal of Hydrology, 377, 80-91, https://doi.org/10.1016/j.jhydrol.2009.08.003, 2009.

Hammami, D., Lee, T. S., Ouarda, T. B. M. J., and Lee, J.: Predictor selection for downscaling GCM data with LASSO, Journal of Geophysical Research: Atmospheres, 117, https://doi.org/10.1029/2012JD017864, 2012.

Hersbach, H., Bell, B., Berrisford, P., Hirahara, S., Horányi, A., Muñoz-Sabater, J., Nicolas, J., Peubey, C., Radu, R., and Schepers, D.: The ERA5 global reanalysis, Quarterly Journal of the Royal Meteorological Society, 146, 1999-2049, 2020. 
Hsu, P.-C., Li, T., You, L., Gao, J., and Ren, H.-L.: A spatial-temporal projection model for 10-30 day rainfall forecast in South China, Climate Dynamics, 44, 1227-1244, 10.1007/s00382-014-2215-4, 2015.

Hsu, W.-r. and Murphy, A. H.: The attributes diagram A geometrical framework for assessing the quality of probability forecasts, International Journal of Forecasting, 2, 285-293, 1986.

Hwang, S.-O., Schemm, J.-K. E., Barnston, A. G., and Kwon, W.-T.: Long-Lead Seasonal Forecast Skill in Far Eastern Asia Using Canonical Correlation Analysis, Journal of Climate, 14, 3005-3016, 10.1175/15200442(2001)014<3005:LLSFSI>2.0.CO;2, 2001.

Jia, X., Chen, L., Ren, F., and Li, C.: Impacts of the MJO on winter rainfall and circulation in China, Advances in Atmospheric Sciences, 28, 521-533, 10.1007/s00376-010-9118-z, 2011.

Kirono, D. G., Chiew, F. H., and Kent, D. M.: Identification of best predictors for forecasting seasonal rainfall and runoff in Australia, Hydrological Processes, 24, 1237-1247, 2010.

Kling, H., Fuchs, M., and Paulin, M.: Runoff conditions in the upper Danube basin under an ensemble of climate change scenarios, Journal of Hydrology, 424-425, 264-277, https://doi.org/10.1016/j.jhydrol.2012.01.011, 2012.

Lang, Y., Ye, A., Gong, W., Miao, C., Di, Z., Xu, J., Liu, Y., Luo, L., and Duan, Q.: Evaluating Skill of Seasonal Precipitation and Temperature Predictions of NCEP CFSv2 Forecasts over 17 Hydroclimatic Regions in China, Journal of Hydrometeorology, 15, 1546-1559, 10.1175/JHM-D-13-0208.1, 2014.

Lee, J.-Y., Wang, B., Wheeler, M. C., Fu, X., Waliser, D. E., and Kang, I.-S.: Real-time multivariate indices for the boreal summer intraseasonal oscillation over the Asian summer monsoon region, Climate Dynamics, 40, 493509, 10.1007/s00382-012-1544-4, 2013.

Lepore, C., Tippett, M. K., and Allen, J. T.: ENSO-based probabilistic forecasts of March-May U.S. tornado and hail activity, Geophysical Research Letters, 44, 9093-9101, https://doi.org/10.1002/2017GL074781, 2017.

Leung, J. C.-H. and Qian, W.: Monitoring the Madden-Julian oscillation with geopotential height, Climate Dynamics, 49, 1981-2006, 10.1007/s00382-016-3431-x, 2017.

Li, W., Hsu, P.-C., He, J., Zhu, Z., and Zhang, W.: Extended-range forecast of spring rainfall in southern China based on the Madden-Julian Oscillation, Meteorology and Atmospheric Physics, 128, 331-345, 10.1007/s00703-0150418-9, 2016.

Li, Y., Wu, Z., He, H., Wang, Q. J., Xu, H., and Lu, G.: Post-processing sub-seasonal precipitation forecasts at various spatiotemporal scales across China during boreal summer monsoon, Journal of Hydrology, 125742, 2020. 
Lima, C. H. R. and Lall, U.: Hierarchical Bayesian modeling of multisite daily rainfall occurrence: Rainy season onset, peak, and end, Water resources research, 45, 2009.

Lima, C. H. R. and Lall, U.: Spatial scaling in a changing climate: A hierarchical bayesian model for non-stationary multi-site annual maximum and monthly streamflow, Journal of Hydrology, 383, 307-318, 2010.

Livezey, R. E. and Chen, W. Y.: Statistical Field Significance and its Determination by Monte Carlo Techniques, Monthly Weather Review, 111, 46-59, 10.1175/1520-0493(1983)111<0046:SFSAID>2.0.CO;2, 1983.

Lü, A., Jia, S., Zhu, W., Yan, H., Duan, S., and Yao, Z.: El Niño-Southern Oscillation and water resources in the headwaters region of the Yellow River: links and potential for forecasting, Hydrology and Earth System Sciences, 15, 1273-1281, 2011.

Madden, R. A. and Julian, P. R.: Detection of a 40-50 Day Oscillation in the Zonal Wind in the Tropical Pacific, Journal of Atmospheric Sciences, 28, 702-708, 10.1175/1520-0469(1971)028<0702:Doadoi>2.0.Co;2, 1971.

Madden, R. A. and Julian, P. R.: Description of Global-Scale Circulation Cells in the Tropics with a 40-50 Day Period, Journal of Atmospheric Sciences, 29, 1109-1123, 10.1175/1520-0469(1972)029<1109:DOGSCC>2.0.CO;2, 1972.

McInerney, D., Kavetski, D., Thyer, M., Lerat, J., and Kuczera, G.: Benefits of Explicit Treatment of Zero Flows in Probabilistic Hydrological Modeling of Ephemeral Catchments, Water Resources Research, 55, 11035-11060, https://doi.org/10.1029/2018WR024148, 2019.

McNeish, D. M.: Using Lasso for Predictor Selection and to Assuage Overfitting: A Method Long Overlooked in Behavioral Sciences, Multivariate Behavioral Research, 50, 471-484, 10.1080/00273171.2015.1036965, 2015.

Mekanik, F., Imteaz, M., Gato-Trinidad, S., and Elmahdi, A.: Multiple regression and Artificial Neural Network for long-term rainfall forecasting using large scale climate modes, Journal of Hydrology, 503, 11-21, 2013.

Michaelsen, J.: Cross-Validation in Statistical Climate Forecast Models, Journal of Applied Meteorology and Climatology, 26, 1589-1600, 10.1175/1520-0450(1987)026<1589:CVISCF>2.0.CO;2, 1987.

Nardi, Y. and Rinaldo, A.: Autoregressive process modeling via the Lasso procedure, Journal of Multivariate Analysis, 102, 528-549, https://doi.org/10.1016/j.jmva.2010.10.012, 2011.

Ouyang, Y. and Liu, F.: Intraseasonal variability of summer monsoon rainfall over the lower reaches of the Yangtze River basin, Atmospheric and Oceanic Science Letters, 13, 323-329, 10.1080/16742834.2020.1741322, 2020.

Peel, M. C., Finlayson, B. L., and McMahon, T. A.: Updated world map of the Köppen-Geiger climate classification, Hydrol. Earth Syst. Sci., 11, 1633-1644, 10.5194/hess-11-1633-2007, 2007. 
Pegion, K., Kirtman, B. P., Becker, E., Collins, D. C., LaJoie, E., Burgman, R., Bell, R., DelSole, T., Min, D., and Zhu, Y.: The Subseasonal Experiment (SubX): A multimodel subseasonal prediction experiment, Bulletin of the American Meteorological Society, 100, 2043-2060, 2019.

Peng, Z., Wang, Q. J., Bennett, J. C., Pokhrel, P., and Wang, Z.: Seasonal precipitation forecasts over China using monthly large-scale oceanic-atmospheric indices, journal of hydrology, 519, 792-802, 10.1016/J.JHYDROL.2014.08.012, 2014.

Ren, H. and Shen, Y.: A New Look at Impacts of MJO on Weather and Climate in China (in Chinese), Advances in Meteorological Science and Technology, 6, 97-105, 2016.

Renard, B.: A Bayesian hierarchical approach to regional frequency analysis, Water Resources Research, 47, https://doi.org/10.1029/2010WR010089, 2011.

Reza Najafi, M. and Moradkhani, H.: Analysis of runoff extremes using spatial hierarchical Bayesian modeling, Water Resources Research, 49, 6656-6670, https://doi.org/10.1002/wrcr.20381, 2013.

Robertson, A. and Vitart, F.: Sub-seasonal to Seasonal Prediction: The Gap Between Weather and Climate Forecasting, Elsevier2018.

Roman, S., Thordis, L. T., and Tilmann, G.: Uncertainty Quantification in Complex Simulation Models Using Ensemble Copula Coupling, Statistical Science, 28, 616-640, 10.1214/13-STS443, 2013.

Schepen, A. and Wang, Q. J.: Toward Accurate and Reliable Forecasts of Australian Seasonal Rainfall by Calibrating and Merging Multiple Coupled GCMs, Monthly Weather Review, 141, 4554-4563, 10.1175/MWR-D-12-00253.1, 2013.

Schepen, A., Wang, Q. J., and Robertson, D.: Evidence for Using Lagged Climate Indices to Forecast Australian Seasonal Rainfall, Journal of Climate, 25, 1230-1246, 10.1175/jcli-d-11-00156.1, 2012.

Schepen, A., Wang, Q. J., and Robertson, D. E.: Seasonal Forecasts of Australian Rainfall through Calibration and Bridging of Coupled GCM Outputs, Monthly Weather Review, 142, 1758-1770, 10.1175/MWR-D-13-00248.1, 2014.

Schepen, A., Zhao, T., Wang, Q. J., and Robertson, D. E.: A Bayesian modelling method for post-processing daily sub-seasonal to seasonal rainfall forecasts from global climate models and evaluation for 12 Australian catchments, Hydrology Earth System Sciences, 22, 1615-1628, 2018.

Sohrabi, S., Brissette, F. P., and Arsenault, R.: Coupling large-scale climate indices with a stochastic weather generator to improve long-term streamflow forecasts in a Canadian watershed, Journal of Hydrology, 594, 
125925, https://doi.org/10.1016/j.jhydrol.2020.125925, 2021.

Specq, D. and Batté, L.: Improving subseasonal precipitation forecasts through a statistical-dynamical approach : application to the southwest tropical Pacific, Climate Dynamics, 55, 1913-1927, 10.1007/s00382-020-05355-7, 2020.

Strazzo, S., Collins, D. C., Schepen, A., Wang, Q. J., Becker, E., and Jia, L.: Application of a Hybrid Statistical?Dynamical System to Seasonal Prediction of North American Temperature and Precipitation, Monthly Weather Review, 147, 607-625, 10.1175/MWR-D-18-0156.1, 2019.

Totz, S., Tziperman, E., Coumou, D., Pfeiffer, K., and Cohen, J.: Winter Precipitation Forecast in the European and Mediterranean Regions Using Cluster Analysis, Geophysical Research Letters, 44, 12,418-412,426, https://doi.org/10.1002/2017GL075674, 2017.

Tuel, A. and Eltahir, E. A. B.: Seasonal Precipitation Forecast Over Morocco, Water Resources Research, 54, 91189130, https://doi.org/10.1029/2018WR022984, 2018.

Vehtari, A. and Lampinen, J.: Bayesian Model Assessment and Comparison Using Cross-Validation Predictive Densities, Neural Computation, 14, 2439-2468, 10.1162/08997660260293292, 2002.

Vernieuwe, H., Vandenberghe, S., De Baets, B., and Verhoest, N. E. C.: A continuous rainfall model based on vine copulas, Hydrol. Earth Syst. Sci., 19, 2685-2699, 10.5194/hess-19-2685-2015, 2015.

Vigaud, N., Tippett, M. K., Yuan, J., Robertson, A. W., and Acharya, N.: Spatial Correction of Multimodel Ensemble Subseasonal Precipitation Forecasts over North America Using Local Laplacian Eigenfunctions, Monthly Weather Review, 148, 523-539, 10.1175/MWR-D-19-0134.1, 2020.

Vitart, F. and Robertson, A. W.: The sub-seasonal to seasonal prediction project (S2S) and the prediction of extreme events, npj Climate Atmospheric Science, 1, 1-7, 2018.

Vitart, F., Ardilouze, C., Bonet, A., Brookshaw, A., Chen, M., Codorean, C., Déqué, M., Ferranti, L., Fucile, E., and Fuentes, M.: The subseasonal to seasonal (S2S) prediction project database, Bulletin of the American Meteorological Society, 98, 163-173, https://doi.org/10.1175/BAMS-D-16-0017.1, 2017.

Vitart, F., Robertson, A., Kumar, A., Hendon, H., Takaya, Y., Lin, H., Arribas, A., Lee, J., Waliser, D., and Kirtman, B.: Subseasonal to seasonal prediction: Research implementation plan, WWRP/THORPEX-WCRP Report, 2012. in Python, PeerJ, 2, https://doi.org/10.7717/peeri.453, 2014.

Wang, B. and Xie, X.: A Model for the Boreal Summer Intraseasonal Oscillation, Journal of the Atmospheric Sciences, 
54, 72-86, 10.1175/1520-0469(1997)054<0072:AMFTBS>2.0.CO;2, 1997.

Wang, M. and Duan, A.: Quasi-Biweekly Oscillation over the Tibetan Plateau and Its Link with the Asian Summer Monsoon, Journal of Climate, 28, 4921-4940, 10.1175/JCLI-D-14-00658.1, 2015.

Wang, Q. J., Robertson, D. E., and Chiew, F. H. S.: A Bayesian joint probability modeling approach for seasonal forecasting of streamflows at multiple sites, Water Resources Research, 45, https://doi.org/10.1029/2008WR007355, 2009.

Wang, Q. J., Shrestha, D. L., Robertson, D. E., and Pokhrel, P.: A log-sinh transformation for data normalization and variance stabilization, Water Resources Research, 48, https://doi.org/10.1029/2011WR010973, 2012.

Wang, Z.: Climate variability of summer rainfalls in China and the possible mechanism (in Chinese), Chinese Academy of Sciences, 2007.

Wheeler, M. C. and Hendon, H. H.: An All-Season Real-Time Multivariate MJO Index: Development of an Index for Monitoring and Prediction, Monthly Weather Review, 132, 1917-1932, 10.1175/15200493(2004)132<1917:AARMMI>2.0.CO;2, 2004.

Woolnough, S. J.: Chapter 5 - The Madden-Julian Oscillation, in: Sub-Seasonal to Seasonal Prediction, edited by: Robertson, A. W., and Vitart, F., Elsevier, 93-117, https://doi.org/10.1016/B978-0-12-811714-9.00005-X, 2019.

Wu, Z., Xu, Z., Wang, F., He, H., Zhou, J., Wu, X., and Liu, Z.: Hydrologic Evaluation of Multi-Source Satellite Precipitation Products for the Upper Huaihe River Basin, China, Remote Sensing, 10, 10.3390/rs10060840, 2018.

Yeo, I. and Johnson, R. A.: A new family of power transformations to improve normality or symmetry, Biometrika, 87, 954-959, 2000.

Zhang, C.: Madden-Julian Oscillation, Review of Geophysics, 43, https://doi.org/10.1029/2004RG000158, 2005.

Zhang, L. and Singh, V. P.: Bivariate rainfall frequency distributions using Archimedean copulas, Journal of Hydrology, 332, 93-109, https://doi.org/10.1016/j.jhydrol.2006.06.033, 2007.

Zhang, L., Wang, B., and Zeng, Q.: Impact of the Madden-Julian Oscillation on Summer Rainfall in Southeast China, Journal of Climate, 22, 201-216, 10.1175/2008JCLI1959.1, 2009.

Zhu, Z. and Li, T.: The statistical extended-range (10-30-day) forecast of summer rainfall anomalies over the entire China, Climate Dynamics, 48, 209-224, 10.1007/s00382-016-3070-2, 2017. 